\title{
Analysis of the Need for Legislation of Chinese Basic Medical Services
}

\author{
Zimin Chen \\ Hubei University of Science and Technology \\ School of Basic Medical Science \\ HuBei, China \\ 449138671@qq.com
}

\author{
Chenglong Xiong \\ Fudan University \\ School of Public Health \\ Shanghai, China
}

\author{
Guozhong He* \\ Kunming Medical University \\ School of Public Health \\ Kunming, China \\ hegzh2002@aliyun.com \\ *Corresponding author
}

\begin{abstract}
For many years, China has had no unified legislation dealing with basic medical services. Instead of legal documents, the basic medical service system only exists as a set of policy files, but the citizens' right to health and basic medical care failed to be fully realized due to the insufficient power of such policy files. Thus it is necessary to legislate, and basic medical service legislation should clearly define what should be provided by the basic medical services, strengthen the government's financial guarantees, regulate basic medical service prices, and assure citizens' basic right to medical services. Such legislation would fully guarantee citizens' basic right to medical services, fully mobilize social medical resources, and improve the quality of basic medical services.
\end{abstract}

Keywords-Basic Medical System; Basic Medical Services; Government Responsibility; Legislation

\section{ANALYSiS OF INSTITUTIONAL CHANGES Of CHINESE MEDICAL SERVICES}

The Chinese medical service system has gone through three stages after the foundation of new China[1] in 1949. The first stage was the Welfare Pattern in the planned economy. The Welfare Pattern of the health care system implemented by the Chinese government from the 1950s to 1970s was based on the Communist Party of China (CPC's) experiences and core ideas in the revolutionary war. During this time, the medical security system was adapted to the planned economy and played an important role in safeguarding people's health, promoting the development of medical and health services, and maintaining social stability.

The second stage was the Hybrid Pattern in place during the economic transformation period from the 1980s to 1997. This period saw major changes to China's social economy, but the health care system of free medical care and labor insurance medical treatment was unable to adapt to the requirements of the socialist market economy system. Disadvantages of the traditional workers medical treatment insurance system became more and more prominent, and the government had to seek new ways of providing health care to its citizens[2].

The third stage was the Security Pattern from 1998 to 2009. In the process of transforming from a planned economy to a market economy, many major changes took place in the area of basic health care services, and significant changes also took place in health-management operation mechanisms that derived from those of the planned economy era. However, these changes were not harmonious, were out of sync with each other, and were often contradictory to each other.[3]

The new health-care reform in China released on April 6, 2009, provided an outline for implementing the new reforms and a framework for providing "universal coverage" by 2020 . The major emphasis of the reforms is to consider the basic medical and health care system as a kind of public good. Such a system treats health care as a publically available product that benefits everyone, and it marks a further shift of government functions to individual service providers. China has made considerable achievements in providing basic medical services; however, there are still many problems such as services being too expensive and long wait times to receive treatment.

\section{URGENCY AND NECESSITY OF CHINESE BASIC MEDICAL SERVICES LEGISLATION}

China has not yet formulated any special legislation for providing basic medical services, and the existing regulations concerning basic medical care are a mixture of low-level, inconsistent, and insufficient policies. This has led to a number of social problems. 
A. Improvement in quality and the expansion of basic medical services requires that high-level authorities provide consistent explanations of the coverage provided by the basic medical services

Because the concepts of basic medical services have not been clearly defined by government officials, there are numerous controversies among scholars about how basic medical services should be understood and how they should be provided. For example, Zhang Hongcai said: “Compared with specialized medical services, basic medical services specifically refer to the medical services necessary for the survival and development of the residents, and they are available to everyone and government financing and affordable."[4] Ding Shujuan said the definition should consider the following factors: "The government should operate with expectations of providing for individual citizens' health, dealing with epidemics, and ensuring the basic health of population; it should choose projects based on the results of cost-effectiveness analysis; and it should ensure fairness and efficiency in funding."[5] Chen Hui add: "Basic medical services are those services that the government should ensure all residents receive, and the main source of funds is public finance; the auxiliary medical service funds are mainly from the individuals or families.”[6]

Without clear definition of its concept and meaning, it is hard to define the range of basic medical services. This will undoubtedly influence the quality and range of basic medical services that the population can enjoy.

\section{B. The state's responsibility for basic medical services should be clearly stipulated by law}

The legal basis for the state's responsibility to provide basic medical services can be found in The Constitution of The People's Republic of China. Article 21 states: "The state develops medical and health services; promotes modern medicine and traditional Chinese medicine; encourages and supports the setting up of various medical and health facilities by the rural economic collectives, state enterprises and institutions, and neighborhood organizations; and promotes health and sanitation activities of a mass character all for the protection of the people's health." Article 45 states: "Citizens of the People's Republic of China have the right to material assistance from the state and society when they are old, ill, or disabled. The state develops the social insurance, social relief, and medical and health services that are required for citizens to be able to enjoy this right." As the fundamental law of the nation, the statements in the constitution are not very specific; therefore, the establishment of the basic medical system must have matching laws and regulations.

Almost all major reform measures in China stay at the policy level, but in this situation reasonable expectations of the citizens for their right to receive health care cannot be realized. There is almost no complete legal system in the field of basic medical insurance. There are scattered regulations in the "Social insurance law", but these regulations are only roughly written, and they do not stipulate the responsibility of the government clearly and in detail. This leads to a lack of statesponsored basic medical services. Therefore, from the perspective of safeguarding citizens' access to basic medical services, it is urgent the government devise a basic medical service act that clearly stipulates the obligation of government to provide basic medical services and ensures that citizens' right to health services is guaranteed.

\section{A uniform medical services act is needed to eliminate the imbalance in the development of basic medical services}

China is a country with a vast territory and large population, and development between different regions and between urban and rural areas is uneven. The level of development of basic medical services within a region is influenced by the region's economic, political, social, cultural, and other factors. Currently, the development of Chinese basic medical services is imbalanced, and as Jiang Xin points out: “At present, the resource allocation of basic medical services, the availability of health services, and the quality and quantity of basic medical services are obviously imbalanced. There is a gap in rural areas and in the cities in terms of health care personnel, funds, facilities, equipment, etc."[7] Thus China needs to include in a basic medical service law that funds and technology should lean toward less developed areas.

\section{A unified basic medical service act is needed to ensure that all patients pay the same for the same treatments}

The existing medical regulatory documents do not clarify the rules, thus some treatments that would normally fall under the scope of the basic medical services are pushed into the open market. Under market conditions, patients might pay a higher price for the same treatments. "In a medical services market, the patient has a lack of knowledge of medical products and services, and this, along the sudden onset of illness or injury and need for timely treatment; means the interactions between patients and doctors are unequal. In the case of such information asymmetry, patients tend to pay a higher price for the same treatment. ”[8]

With recent developments in the national economy and society, and people's rising health demands, the current fragmented and complicated health service regulatory documents currently being used to guide basic medical services in China cannot satisfy the public's health care needs; thus it is urgent to create a special basic medical service law.[9] The basic medical services is an important livelihood issue, and the lack of institutional guarantees for health care services affects social stability and has a negative effect on the overall welfare. Because basic medical service legislation in China has many deficiencies, it might be useful to investigate experiences with basic medical service legislation outside the country.

\section{HEALTH-CARE LEGISLATION IN DEVELOPED COUNTRIES}

The medical security systems of developed countries such as the UK, the US, and Canada have experienced long histories of development, and when seen from a systems development and evolutionary perspective, it is clear that most of the developed countries pay great attention to regulatory functions and the leading role of basic medical services in maintaining the health of the population. 


\section{A. British health-care legislation}

As early as 1858, Britain enacted Medical Act 1858 as its first comprehensive piece of legislation regarding medical care. In 1946, the country enacted the National Health Service Act in the form of a single law to institutionalize the government's responsibility for public health care. The establishment of the British National Health Service made health care a legal obligation of the government so that all citizens could have fair and equal access to basic health care services provided by the State. Although public health care is not a public product, according to the law the British government must provide medical services to its citizens so that every citizen can have equal access to treatment and enjoy the same basic medical benefits provided by the government. Britain also issued the Drug Act 1954, Dentists Act 1984, Ophthalmologist Law 1989, and other professional health care laws. As Chen Changxiong et al. described: "Britain's medical legislation lacks focus, and it does not have a unified law as a whole to guide the medical industry; neither the Health Act 1999 nor the National Health Service Act 2006 have established the fundamental principle and system for the entire health sector."[10] However, it must be noted that the UK health services are comprehensively protected by legislation in the first place, and the government responsibility has been highlighted, namely, to use taxes to purchase medical services covering the vast majority people.

\section{B. US health care legislation}

In 1935, the US issued the Social Security Act to ensure economic assistance for the elderly poor in each fiscal year, and the Medical Care and Assistance Act issued in 1965 emphasized the state's responsibility for health care for the elderly. The aim of the Medicare Prescription Drug, Improvement, and Modernization Act of 2003 was to improve the medical services for the elderly and to reduce the medical burden on the government at the same time. In 2010, the US Congress passed the Patient Protection and Affordable Care Act that aims to improve health care coverage, reduce medical costs, and improve the quality and accessibility of medical services.

The original Social Security Act was not only a landmark in the entirety of human social security history, but it also became the impetus for the US to try to perfect the medical security system. This has followed the tradition of paying attention to legal system construction and adhering to administration based on law, thus attempts to reform and perfect the medical security system in the US has been driven primarily by legislation.[7]

\section{Canadian health-care legislation}

Canada issued the Hospital Insurance and Diagnostic Services Act and the National Health Service Act in 1957 and 1966, respectively. Both pieces of legislation regulate the proportion of medical treatment charges and delineate the responsibilities of the governments. The Canada Health Act of 1984 also defines the government's share of medical costs, and today it forms Canada’s universal health care system.[8]

Obviously, developed countries such as the UK, the US, and Canada all pay special attention to health-care legislation and make full use of the law to develop medical services, while at the same time they stress the state's responsibility to provide medical services.

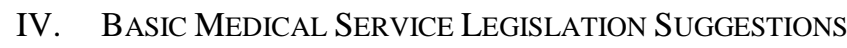

It is well known that the rule of law is the foundation of modern states and that good law is the premise of good governance. The criteria for judging good and bad laws mainly involves determining if it has humanistic concerns and if they are based on the concept of caring about the public health of the entire population. Legislation regarding the basic medical care system is the specific implementation of such a process and is the result of adhering to the concept of providing health care for everyone.

The level of development of a basic medical service must be coordinated with national economic and social development, and the welfare level of the people's health must be adapted to their economic development level. Therefore, when we are learning from the successful experiences of basic medical services in developed countries, we cannot ignore China's actual economic and social level of development. Thus China must consider the distribution of medical resources through the basic medical service, the medical burden of the population, and various factors such as the government's financial resources in order to make basic medical services legislation suitable to the country's situation.

We propose that the following principles are important for China to consider when developing its basic medical service legislation.

\section{A. Give clear definitions of basic medical services.}

The definition provided by law is an essential tool necessary for legal. There is a close connection between basic medical services and the national and regional level of economic development, and such services fluctuate with changes in economic and social development. However, providing a clear definition is difficult. Thus, the state can try to use enumerated methods of legislation, i.e., giving examples of those who fall under the scope of basic medical services and stipulating the minimum range of basic medical services that must be provided by the local government. At the same time, legislation should leave some room for interpretation by the local government so that local government has the power to gradually raise the level of the basic medical services it provides.

\section{B. Strengthen the government's financial responsibility for} basic medical services and give it the power to supervise prices.

Structural reform inevitably represents the values that a nation intends to achieve. For the legislation of basic medical services, it is necessary to reform the existing liability structure and to clarify the basic medical service responsibility of governments at all levels.

A basic medical services act should clearly define the financial responsibility of the government in order to avoid a lack of sufficient funds. Legislative stipulation of the medical 
treatment duties of the federal and provincial governments in Canada is a good example of this.

In addition, the law should specify the government's responsibility for supervising prices, it should ensure that national funds are only used to improve basic medical services, and that there is no collusion between government officials and those regulated by the legislation, which can violate the patients' rights. This is important because "in the process of the specific regulation, regulatory officials - often for their own self-interest-might collude with those being regulated privately and act to shield those being regulated or even to formulate or implement measures according to the interests of those being regulated."

\section{Basic medical services should lean toward less developed areas as much as possible.}

The unbalanced economic and social development between urban and rural areas in China cannot be changed in a short time. Thus the legislation on basic medical services should not only pay attention to formal equality, but also should pay more attention to substantive equality. In order to allow citizens of the whole nation to enjoy the economic development achievements of the country, the basic medical service legislation cannot be rigidly uniform. Instead, basic medical service legislation should focus on less developed areas compared to those that are already well developed. The goal is to avoid the situation where different members of the public enjoy different medical services because of the different levels of economic development in different areas.

\section{The state should compensate private medical institutions for participating in the basic medical services.}

With the enlargement of the scope of basic medical services, the lack of medical resources will become increasingly evident. If only relying on public hospitals, it will be impossible to meet the needs of patients' basic medical services in China. Thus the private medical institutions should be allowed to participate in providing basic medical services.

The purpose of private medical institutions is to make a profit, thus private medical institutions should be fairly compensated by the government for providing basic medical services. This would likely encourage more private medical institutions to actively participate in providing basic medical services.

\section{E. The act should regulate ways to seek remedy when citizens' basic service rights are violated.}

If there is no legal relief when rights are violated, then the law will be meaningless. Even if a basic medical services act is produced that regulates the government's financial responsibility and power over prices, the act must still ensure citizens' right to bring administrative prosecution if the government does not appropriately meet its financial responsibilities and price regulating responsibilities.

The improvement in the quality and range of basic medical services will not occur solely through the government support as provided for in any basic medical services act. As mentioned earlier, the legislation should also encourage private hospitals and non-governmental organizations to participate in providing the basic medical services so as to jointly improve the quality and scope of basic medical services in China.

\section{CONCLUSION}

The exiting medical service normative documents in China are insufficient to fully guarantee citizens' right basic medical services, to fully mobilize social medical resources, and to improve the quality of basic medical services for the population. It is imperative to formulate basic medical laws consistent with the national level of economic and social development.

\section{ACKNOWLEDGMENT}

This work was supported by the National Natural Science Foundation of China (NSFC, No. 71363001 and 71473073). We are also grateful to Dr. Song Xiao and Fenglian Jiang for their help in preparing the manuscript.

\section{REFERENCES}

[1] He Guozhong. Research on China's health policy evaluation [M]. Guiyang: Guizhou science and technology press, 2011.05.(In Chinese)

[2] Chu Tingyong. China's medical security system development research, based on the perspective of international comparison. Northeast university of finance and economics Ph.D. Thesis, Doctoral dissertation defense time: June 2012: 34. (In Chinese)

[3] Zhang Hong. Some Issues on basic medical services [J]. Health Economics Research, 2012, (2): 10. (In Chinese)

[4] Jiang Xin, Luo Jia. Analysis of the current situation and Countermeasures of urban and rural basic medical and health equality in China [J]. South China Rural Area, 2012, (3): 15. (In Chinese)

[5] Zhan Guobin, Zhou Lin. Defects of basic medical service price regulation and its improvement strategies [J]. Journal of Fujian Provincial Committee Party School of CPC [J], 2013, (2): 76. (In Chinese)

[6] Xiao Song, He Guozhong,Luo Wujin.Chinese health legislation urgency from the perspective of comparative study [J]. China Health Law, 2008, 16 (1): 7-8. (In Chinese)

[7] Chen Changxiong, Wei liangyu. General introduction to British legal system of medical and health care [J]. China Health Law, 2011, (115): 21. (In Chinese)

[8] Zuo Liancun. The development of Canadian medical insurance system and its enlightenment for China [J]. Strategy Research, 2013 (5): 75. 